BMJ

Open

Gastroenterology

\title{
Worse outcomes and higher costs of care in fibrostenotic Crohn's disease: a real- world propensity-matched analysis in the USA
}

\author{
Melody Dehghan, ${ }^{1}$ Gabriel Wong, ${ }^{1}$ Edward Neuberger, ${ }^{1}$ Cindy Kin, ${ }^{2}$ Florian Rieder, ${ }^{3}$ \\ K T Park ${ }^{1}$
}

To cite: Dehghan M, Wong G, Neuberger $\mathrm{E}$, et al. Worse outcomes and higher costs of care in fibrostenotic Crohn's disease: a real-world propensity-matched analysis in the USA. BMJ Open Gastro 2021;8:e000781. doi:10.1136/ bmjgast-2021-000781

- Additional supplemental material is published online only. To view, please visit the journal online (http://dx.doi. org/10.1136/bmjgast-2021000781).

Received 31 August 2021 Accepted 16 November 2021

Check for updates

(c) Author(s) (or their employer(s)) 2021. Re-use permitted under CC BY-NC. No commercial re-use. See rights and permissions. Published by BMJ.

${ }^{1}$ Genentech Inc, South San Francisco, California, USA 2Department of Surgery, Stanford University School of Medicine, Stanford, California, USA

${ }^{3}$ Department of

Gastroenterology and

Hepatology, Digestive Disease Institute, Cleveland Clinic Foundation, Cleveland, Ohio, USA

Correspondence to KT Park; park.kt@gene.com

\section{ABSTRACT}

Background Patients with Crohn's disease (CD) may develop fibrostenotic strictures. No currently available therapies prevent or treat fibrostenotic CD (FCD), making this a critical unmet need.

Aim To compare health outcomes and resource utilisation between $C D$ patients with and without fibrostenotic disease.

Methods Patients aged $\geq 18$ years with FCD and nonFCD between 30 0ctober 2015 and 30 September 2018 were identified in the Truven MarketScan Commercial Claims and Encounters Database. We conducted 1:3 nearest neighbour propensity score matching on age, sex, malnutrition, payer type, anti-tumour necrosis factor use, and Charlson Comorbidity Index score. Primary outcomes up to 1 year from the index claim were $\geq 1$ hospitalisation, $\geq 1$ procedure, $\geq 1$ surgery, and steroid dependency ( $>100$ day supply). Associations between FCD diagnosis and outcomes were estimated with a multivariable logistic regression model. This study was exempt from institutional review board approval.

Results Propensity score matching yielded 11022 patients. Compared with non-FCD, patients with FCD had increased likelihood of hospitalisations $(17.1 \%$ vs $52.4 \% ; p<0.001)$, endoscopic procedures $(4.4 \%$ vs $8.6 \% ; p<0.001)$, IBD-related surgeries $(4.7 \%$ vs $9.1 \% ; p<0.001)$, steroid dependency $(10.0 \%$ vs $15.7 \%$; $p<0.001$ ), and greater mean annual costs per patient ( $\$ 47$ 575 vs $\$ 77609 ; p<0.001)$. FCD was a significant risk factor for $\geq 1$ hospitalisation (adjusted OR (aOR), 6.1), $\geq 1$ procedure (aOR, 2.1), $\geq 1$ surgery (aOR, 2.0), and steroid dependency (aOR, 1.7).

Conclusions FCD was associated with higher risk for hospitalisation, procedures, abdominal surgery, and steroid dependency. Patients with FCD had a greater mean annual cost per patient. FCD represents an ongoing unmet medical need.

\section{INTRODUCTION}

Crohn's disease (CD) is a type of inflammatory bowel disease (IBD) with a relapsing and remitting disease course. ${ }^{1}$ Various phenotypes of $\mathrm{CD}$ have been characterised according to the Montreal classification based on age at diagnosis, gastrointestinal (GI) tract location, and
Summary box

What is already known about this subject?

$\Rightarrow$ There are no available therapies to prevent or treat fibrostenotic Crohn's disease (CD).

$\Rightarrow$ High rates of intestinal surgery and recurrence of intestinal strictures hallmark this subpopulation of CD patients.

$\Rightarrow$ No large-scale real-world evidence exists describing the health outcomes and direct healthcare costs of fibrostenotic CD patients.

What are the new findings?

$\Rightarrow$ In a given year, compared to CD patients without fibrostenosis, patients with fibrostenosis are approximately twice as likely to be dependent on corticosteroids, have recurrent CD-related surgery or repeated endoscopies, and more than six times more likely to undergo multiple hospitalisations.

$\Rightarrow$ This study represents the first analysis to compare healthcare resource utilisation and costs between CD patients with and without fibrostenosis.

$\Rightarrow$ Costs for patients with fibrostenosis were more than US\$30000 higher per year than for non-FCD patients overall and more than three times the mean annual inpatient costs per patient.

How might it impact on clinical practice in the foreseeable future?

$\Rightarrow$ Fibrostenotic CD represents a persistent unmet need and significant burden on individual patients and the healthcare system.

behaviour of the disease course. ${ }^{2-4}$ Stricturing is the result of ongoing chronic activation of myofibroblasts by inflammation in the GI lining. ${ }^{5-8}$ Despite newer therapies now available or in development for IBD, none are approved for the treatment of fibrosis in IBD, hallmarking a critical unmet medical need for affected patients with fibrostenotic $\mathrm{CD}$ (FCD) ${ }^{8-11}$

Previous research indicates that $>50 \%$ of patients with $\mathrm{CD}$ will develop intestinal strictures in their lifetimes. ${ }^{610}$ Although anti-inflammatory 
medical therapy is the standard of care, the evolution of strictures in FCD is thought to have a parallel pathogenesis that requires add-on antifibrotic treatment. ${ }^{89}$ In light of this, rates of intestinal surgery and recurrence of strictures after surgery remain high and unchanged in FCD. ${ }^{3812-15}$ Furthermore, repeated interventional endoscopic procedures, such as balloon dilation, appear to be a temporising measure with limited long-term usefulness. ${ }^{116-20}$

Understandably, intestinal stricture formation in FCD can be devastating to patients. Scarring from the strictures can lead to intestinal narrowing, ultimately culminating in clinical obstruction. ${ }^{1421}$ Signs and symptoms of clinical obstruction may include abdominal pain, constipation, nausea and vomiting, and, notably, loss of appetite or inability to tolerate foods, leading to chronic malnutrition. ${ }^{22}$

Considering the devastating consequences of untreated stricturing in FCD, it is important to effectively describe the unmet needs in this patient population by characterising health outcomes and costs of care associated with FCD. In this study, we aimed to compare the differences in health outcomes and direct healthcare costs between patients with FCD and patients with $\mathrm{CD}$ without clinical stricturing using a population-based data set in the USA.

\section{METHODS}

\section{Data source}

We performed a retrospective cohort analysis of CD patients using the 2015-2019 Truven MarketScan Commercial Claims and Encounters data set. This database consists of deidentified outpatient, inpatient, and pharmaceutical claims of approximately 40 to 50 million privately insured patients each year. It includes demographic characteristics (age, sex, and geographic region), detailed encounter data (hospital admissions, outpatient visits, and associated procedures), and pharmaceutical data (pharmaceutical claims, day supply, strength, and administrative method). Claims originate from more than 150 large employer-sponsored health insurance plans with patient coverage in all 50 states.

\section{Study population}

We selected a cohort of patients aged $\geq 18$ years who received an inclusive $\mathrm{CD}$ diagnosis $(\mathrm{FCD}$ and $\mathrm{CD}$ without fibrostenotic symptoms (non-FCD) ) between 30 October 2015 and 30 September 2018. To be initially identified as having IBD, patients had to have at least two distinct outpatient visits or one inpatient visit for IBD within 2 years (K50.xx and K51.xx). From this group, we identified patients as having CD if $\geq 80 \%$ of distinct International Statistical Classification of Diseases, Tenth Revision (ICD-10) diagnosis codes were K50.xx. ${ }^{2324}$ For patients to be classified as having FCD, they had to have at least two distinct outpatient visits or one inpatient visit for FCD within 2 years (K50.012, K50.112, K50.812, K50.912). These specific ICD-10 codes were unique to CD-related intestinal obstruction, affecting either the small or the large bowel or both intestinal segments. The requirement of at least two separate coding indicators in the outpatient setting or a hospitalisation for CD-related intestinal obstruction ensures a higher degree of confidence in identifying the FCD subpopulation of interest; similar approaches have reliably identified patient populations with IBD and other conditions using claims data sets. ${ }^{25}{ }^{26}$ For patients diagnosed with FCD, the first FCD-related claim was the index claim (figure 1A). For patients diagnosed with nonFCD, the first CD without fibrostenotic symptoms-related claim was the index claim. We required that patients be continuously enrolled in their insurance plan for $\geq 6$ months before the index claim and $\geq 12$ months afterwards. Patients could not have any autoimmune disease during the study period (spondylitis (M459), nodosa (M300), psoriatic arthritis (L4054, L4059), plaque psoriasis (L400), Wegener (M3130), lupus (M3210), rheumatoid arthritis (M05.x, M06.x), polyangiitis (M317)) or any IBD claims $\geq 6$ months before the index date.

\section{Outcomes and covariates}

The primary outcomes of interest were healthcare resource utilisation (HCRU) markers: steroid dependency (>100 day supply in a year, ${ }^{27} 28 \geq 1$ hospitalisation, $\geq 1$ GI procedure, and $\geq 1$ surgery within a year). Secondary outcomes included mean annual costs per patient: inpatient, outpatient excluding emergency department (ED), outpatient ED, pharmacy, and total cost per patient per year. Patients were classified as receiving corticosteroids based on outpatient or pharmaceutical claims for agents administered orally (not including inhalation) or by injection. ICD and Current Procedural Terminology (CPT) codes were to identify patients undergoing GI procedures and surgeries and were validated by gastroenterologists specialised in IBD (online supplemental appendix).

The primary predictor of interest was FCD versus nonFCD diagnosis. Patients were classified as receiving biologic therapy based on outpatient pharmaceutical claims or Healthcare Common Procedure Coding System (HCPCS) J-codes including infliximab, adalimumab, and certolizumab, vedolizumab, and ustekinumab. Charlson Comorbidity Index (CCI) score was calculated using inpatient and outpatient claims from 6 months preceding the index claim.

\section{Propensity score matching}

To adjust for potential differences regarding baseline characteristics between cohorts, we propensity score matched each patient with FCD to three patients with non-FCD (1:3 ratio) using nearest neighbour matching with a 0.2 calliper. Propensity scores were developed based on age (years), sex, malnutrition (E40-E46 ICD-10), payer type (commercial, Medicare), biologic use (yes/no), and CCI score $(0,1$, or $\geq 2$ ). Propensity score matching was implemented using the proc PSMatch module in SAS Studio 3.7 (SAS Institute; Enterprise edition). $\chi^{2}$ and Student's $t$ tests were used to assess the comparability of baseline characteristics between cohorts for categorical variables and continuous variables, respectively. Student's t tests were used to assess differences 
A

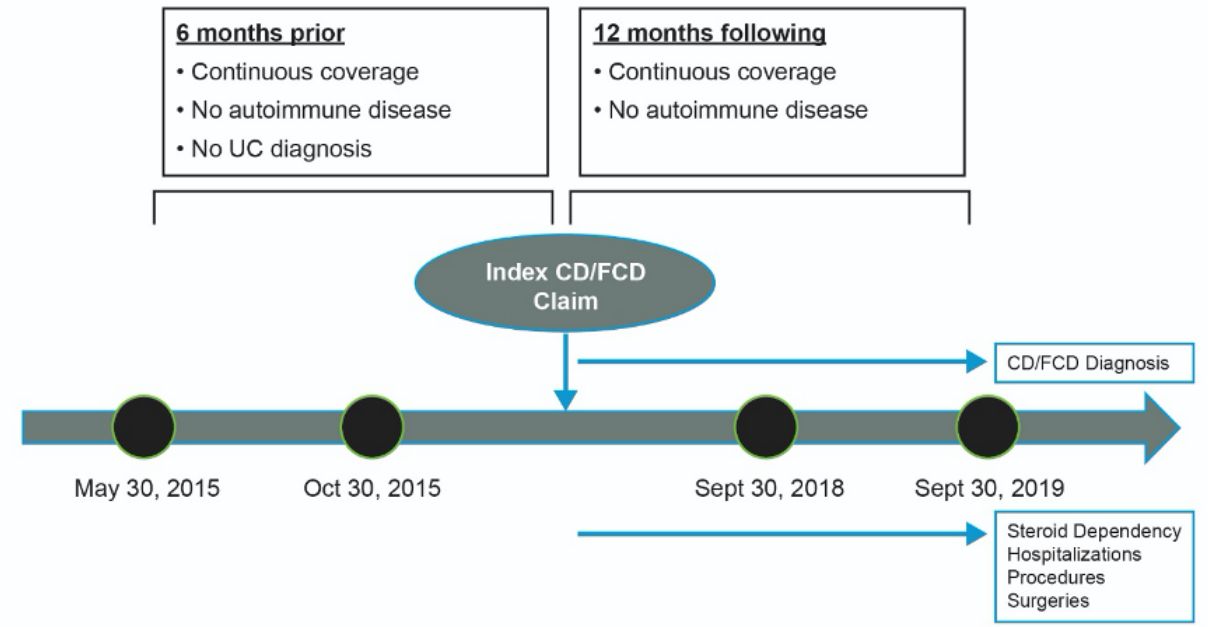

B

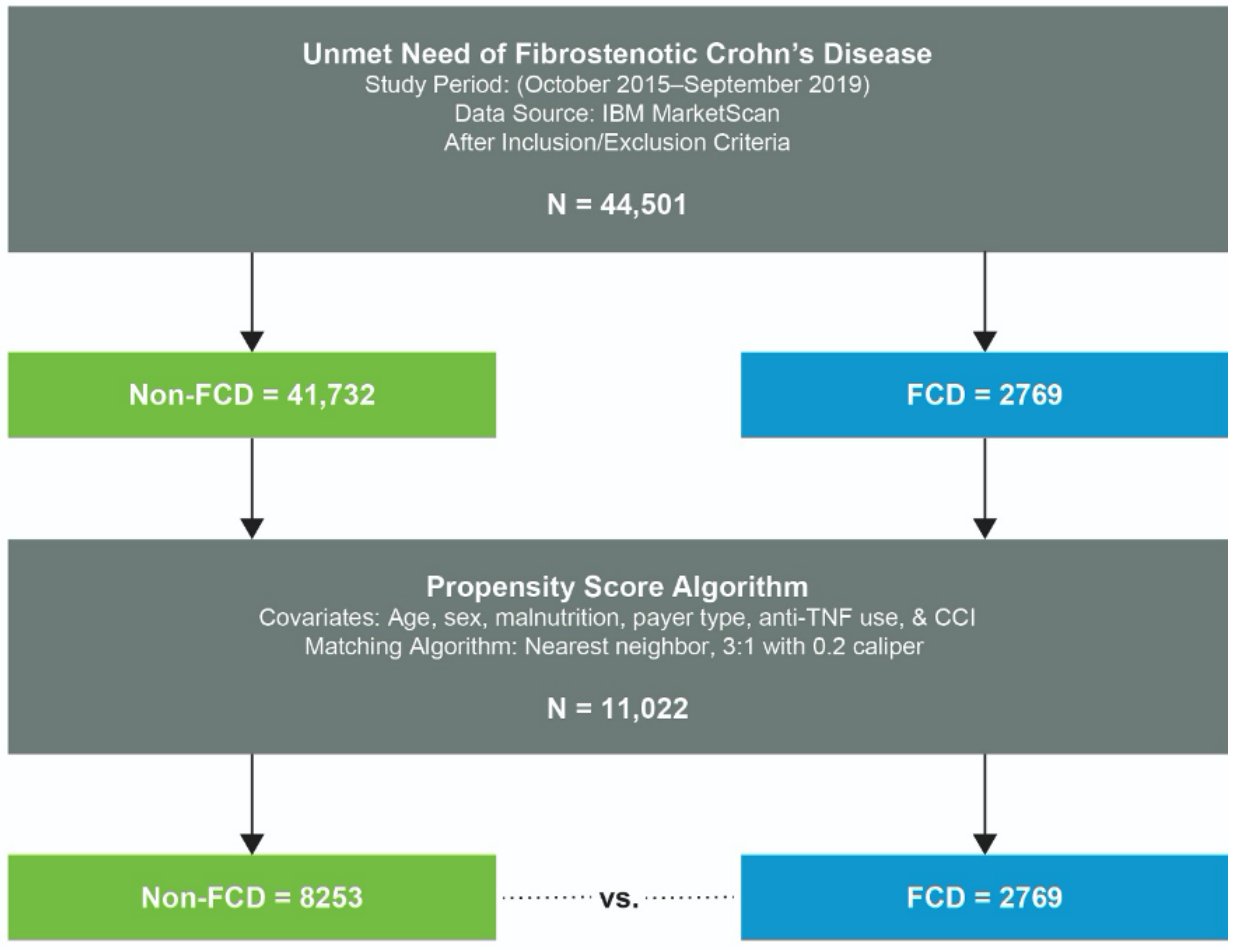

Accuracy of PSM Model

Covariates with standard mean difference $>0.2$ : none

Figure 1 Study design and matching algorithm. (A) Study timeline. (B) Study flow diagram with propensity score matching (PSM). CCI, Charlson Comorbidity Index; CD, Crohn's disease; FCD, fibrostenotic Crohn's disease; TNF, tumour necrosis factor; UC, ulcerative colitis.

in costs between cohorts. All tests for significance were performed at the alpha $=0.05$ level.

\section{Multivariable models}

Multivariable logistic regression models were used to estimate the association between FCD diagnosis and steroid dependency, $\geq 1$ hospitalisation, $\geq 1$ GI procedure, and $\geq 1$ surgery in the propensity score matched cohort. Covariates included FCD diagnosis, age (years), sex, US geographic region (south, north central, northeast, west, unknown), malnutrition, payer type (commercial, Medicare), plan type (preferred provider organisation (PPO), consumer-directed/high deductible health plan (CDHP/ HDHP), health maintenance organisation (HMO), point of service (POS), other, unknown), anti-TNF therapy use, and CCI score $(0,1, \geq 2)$. Referent groups for categorical variables were patients with $\mathrm{CD}$ without fibrostenotic symptoms, male sex, southern region, no malnutrition, commercial payer type, PPO plan type, no anti-TNF 
Table 1 Patient attrition

\begin{tabular}{|c|c|}
\hline & $\mathbf{N}(\%)$ \\
\hline \multicolumn{2}{|l|}{ Inclusion criteria } \\
\hline $\begin{array}{l}\geq 1 \text { inpatient or } \geq 2 \text { outpatient IBD claims from } \\
30 \text { October } 2015 \text { to } 30 \text { September } 2019\end{array}$ & 190899 \\
\hline $\begin{array}{l}\text { Crohn's disease diagnosis ( }>80 \% \text { of claims } \\
\text { for CD) }\end{array}$ & $102188(53.5)$ \\
\hline $\begin{array}{l}\text { Continuous enrolment: } 6 \text { months before, } 12 \\
\text { months after index date }\end{array}$ & $63519(62.2)$ \\
\hline Age $\geq 18$ years & $59062(93.0)$ \\
\hline \multicolumn{2}{|l|}{ Exclusion criteria } \\
\hline No autoimmune disease & 55767 (94.4) \\
\hline No IBD claims in the pre-index period & $44501(79.8)$ \\
\hline Total CD cohort & 44501 \\
\hline \multicolumn{2}{|l|}{ FCD cohort } \\
\hline $\begin{array}{l}\geq 1 \text { inpatient or } \geq 2 \text { outpatient claims of FCD } \\
\text { (on separate days) }\end{array}$ & $2769(6.2)$ \\
\hline
\end{tabular}

CD, Crohn's disease; FCD, fibrostenotic Crohn's disease; IBD, inflammatory bowel disease.

therapy use, and CCI score of 0 . A critical value of 0.05 was specified a priori. All analyses were performed using SAS Studio 3.7 (Enterprise edition).

All authors had access to the study data and reviewed and approved the final manuscript. This study is a retrospective claims database analysis and exempt from institutional review board review.

\section{RESULTS}

\section{Patient demographics}

Between 30 October 2015 and 30 September 2019, 190899 patients with data in the Truven MarketScan database had claims for IBD (table 1). After relevant inclusion and exclusion criteria were applied, a cohort of 47270 patients with CD was included in the study (44 501 with non-FCD and 2769 with FCD). Before propensity score matching, there were significant $(\mathrm{p}<0.001)$ differences between the non-FCD and the FCD cohorts. The FCD cohort was generally older and had higher rates of malnutrition, higher rates of anti-TNF therapy use, and higher CCI scores (online supplemental table 1).

After propensity score matching (figure 1B), 2769 patients with FCD were matched with 8253 patients with non-FCD. No significant differences $(p>0.05$, all variables) were observed between cohorts following propensity score matching (table 2). The mean age for both cohorts was 46.9 years, with equal proportions of men and women, and most patients had commercial insurance $(87.9 \%)$. Of note, related to cost drivers specific to anti-TNF therapy, propensity score matching ensured no differences between groups when considering anti-TNF therapy use. Overall, few patients had malnutrition $(4.6 \%), 36.5 \%$ had received anti-TNF therapy in the preindex period, and most patients had a CCI score of 0 $(50.4 \%)$.

\section{Healthcare resource utilisation}

Annual HCRU was calculated per patient (figure 2). The proportion of patients with $\geq 1$ hospitalisation was significantly higher $(\mathrm{p}>0.001)$ in the FCD cohort $(52.4 \%)$ than in the non-FCD cohort (17.1\%). A similar trend was shown for steroid dependency, with $15.7 \%$ in the FCD cohort and $10.0 \%$ in the non-FCD cohort $(p<0.001)$. The FCD cohort had a significantly $(\mathrm{p}<0.001)$ higher proportion of patients experiencing $\geq 1$ endoscopic procedure (8.6\%) compared with the non-FCD cohort (4.4\%). Consistent with these findings, a higher percentage of

Table 2 Patient demographics after match

\begin{tabular}{|c|c|c|c|c|}
\hline & $\begin{array}{l}\text { Overall } \\
N=11022\end{array}$ & $\begin{array}{l}\text { Non-FCD } \\
\mathrm{N}=8253 \\
(74.9 \%)\end{array}$ & $\begin{array}{l}\text { FCD } \\
\mathrm{N}=2769 \\
(25.1 \%)\end{array}$ & P value \\
\hline Age, mean (SD) & $46.9(16.4)$ & $46.9(16.4)$ & $46.9(16.6)$ & 0.876 \\
\hline Female sex & $5598(50.8)$ & $4200(50.9)$ & $1398(50.5)$ & 0.714 \\
\hline Malnutrition & $502(4.6)$ & $363(4.4)$ & $139(5.0)$ & 0.175 \\
\hline Payer type & & & & \multirow[t]{3}{*}{0.694} \\
\hline Commercial & 9684 (87.9) & 7257 (87.9) & 2427 (87.7) & \\
\hline Medicare & $1338(12.1)$ & $996(12.1)$ & 342 (12.3) & \\
\hline Anti-TNF therapy* & 4021 (36.5) & $3011(36.5)$ & $1010(36.5)$ & 0.993 \\
\hline $\mathrm{CCl}$ & & & & \multirow[t]{4}{*}{0.994} \\
\hline 0 & $5551(50.4)$ & 4154 (50.3) & 1397 (50.5) & \\
\hline 1 & 2238 (20.3) & 1677 (20.3) & $561(20.3)$ & \\
\hline $2+$ & 3233 (29.3) & $2422(29.4)$ & $811(29.3)$ & \\
\hline
\end{tabular}

All data are $n(\%)$ unless otherwise stated.

*Anti-TNF therapy included adalimumab, certolizumab pegol, ustekinumab, vedolizumab, and infliximab.

$\mathrm{CCl}$, Charlson Comorbidity Index; FCD, fibrostenotic Crohn's disease; TNF, tumour necrosis factor. 


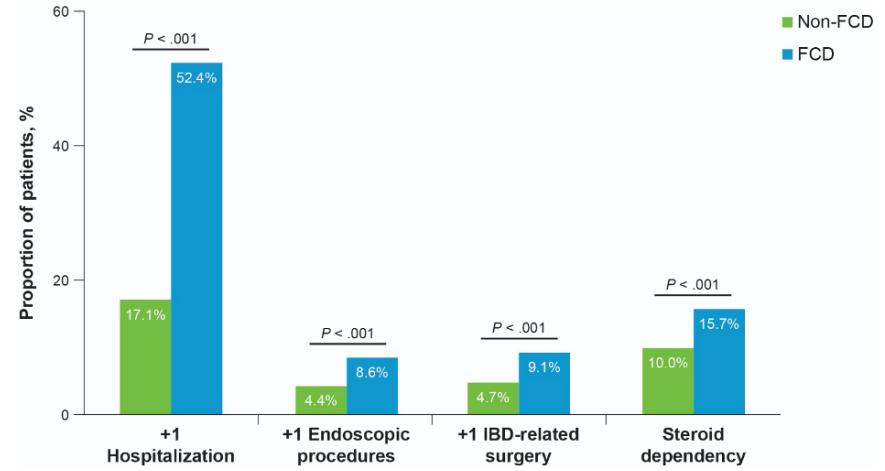

Figure 2 Proportion of annual healthcare resource utilisation between FCD and non-FCD. FCD, fibrostenotic Crohn's disease; IBD, inflammatory bowel disease.

patients with FCD $(9.1 \%)$ than non-FCD $(4.7 \%)$ had $\geq 1$ IBD-related surgery.

Results of the logistic regression (figure 3) adjusting for baseline demographic (age, sex, geographic region, payer type, and plan type) and clinical (malnutrition status, anti-TNF therapy use, CCI score, and CCI category) characteristics found that patients with FCD had significantly higher odds of being hospitalised compared with patients with non-FCD (adjusted OR (aOR), 6.1; $95 \%$ CI, 5.3 to 7.0). Additionally, patients with FCD experienced significantly higher odds of steroid dependency (aOR, 1.7; 95\% CI, 1.4 to 2.0 ) and of undergoing $\geq 1$ GI procedure (aOR, 2.1; 95\% CI, 1.7 to 2.6 ).

\section{Costs}

Annual mean per-patient costs were generally higher for patients with FCD than for patients with non-FCD. Total mean costs were significantly higher for the FCD group (mean, US\$77609 (SD, US\$96 772)) than for the nonFCD group (US $\$ 47575(\$ 74656))(\mathrm{p}<0.001)$. Inpatient, $\mathrm{ED}$, and outpatient costs were all significantly higher in the FCD group ( $<<0.001$, all comparisons) (figure 4$)$. The

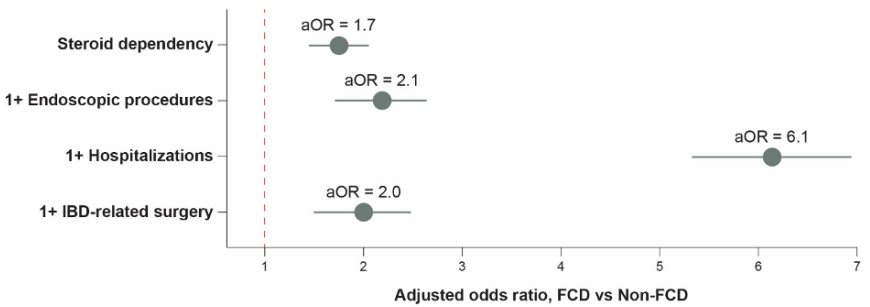

Figure 3 Adjusted OR of HCRU between FCD and nonFCD. Covariates for regression include FCD, age (years), sex, region (south, north central, northeast, west, unknown), malnutrition, payer (CCAE, MDCR), plan type (PPO, CDHP/ HDHP, HMO, POS, other, unknown), anti-TNF therapy use, $\mathrm{CCl}(0,1,2+)$. aOR, adjusted OR; CCAE, Claims and Encounters Data; $\mathrm{CCl}$, Charlson Comorbidity Index; CDHP, consumer-driven health plan; FCD, fibrostenotic Crohn's disease; HCRU, healthcare resource utilisation; HDHP, high-deductible health plan; HMO, health maintenance organisation; IBD, inflammatory bowel disease; MDCR, Medicare; POS, point of service; PPO, preferred provider organisation; TNF, tumour necrosis factor.

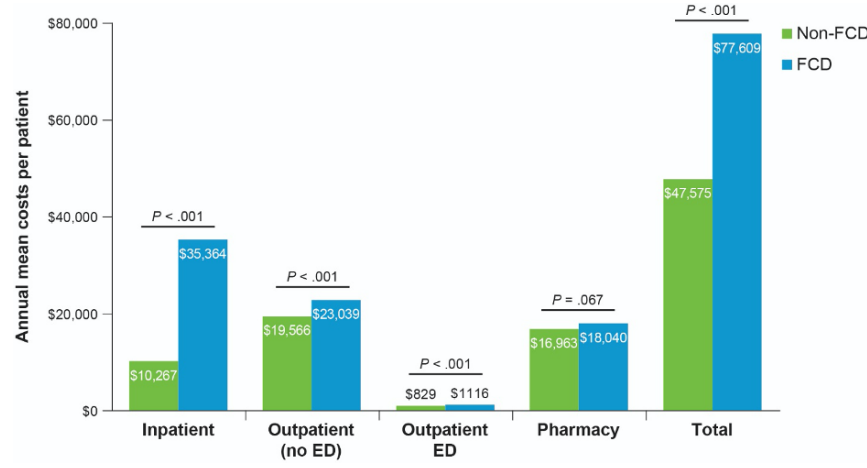

Figure 4 Annual mean costs per patient between FCD and non-FCD. ED, emergency department; FCD, fibrostenotic Crohn's disease.

highest costs for patients with FCD were those associated with inpatient visits, whereas the highest for patients with non-FCD were outpatient costs. Additionally, pharmacyrelated costs were slightly higher for patients with FCD than for patients with non-FCD (FCD, US\$18040 (US\$29 129); non-FCD, US\$16963 (US\$25 966)); however, this difference was not statistically significant $(\mathrm{p}=0.67)$.

\section{DISCUSSION}

Intestinal stricture formation is a common occurrence in CD. Patients with FCD who are living with clinical obstruction are subject to significantly worse health outcomes and increased HCRU than patients without FCD. The findings of our study underscore the persistent unmet medical need in a significant subpopulation of patients with CD. The aims of this study were to characterise the differential health outcomes and healthcare costs in patients with FCD who had clinical obstruction. In unadjusted and adjusted analyses, compared with patients with non-FCD, patients with FCD had approximately twice the increased odds of steroid dependency, progressing to multiple abdominal surgeries, and repeated endoscopic procedures. Strikingly, acute care remains a common medical management requirement. We found that patients with FCD are at $>6 \times$ the risk for multiple hospitalisations in a given year than non-FCD patients. In terms of direct costs to society, on average, HCRU costs for patients with FCD were more than US $\$ 30$ 000 higher per year than for non-FCD patients overall and $>3 \times$ the mean annual inpatient costs per patient.

No antifibrotic therapies have been approved to treat patients with FCD. Although available medical therapies for CD may mitigate symptoms related to inflammation, endoscopic or surgical intervention is often necessary for patients with obstructions caused by stricturing lesions. ${ }^{8-1122}$ Some studies have even implicated anti-TNF therapies in worsening stricture formation and the ensuing obstruction. ${ }^{29-31}$ This notion, however, has been disproven in serial ultrasound studies, the TREAT registry, and the CREOLE cohort. ${ }^{32} 33$ Our analysis highlights the persistent unmet medical need in these patients, who endure worse health outcomes and increased acute 
care utilisation. In addition, to date, our study is the first to compare HCRU and costs between patients with FCD and non-FCD. A previous study evaluating the cost of CD showed correlation between worsening disease, FCD, and higher CD-related surgical exposure. ${ }^{34}$ Patients with CD who undergo CD-related surgeries bear more than twice the burden of cost than patients with moderate to severe CD (US $\$ 101013$ per patient per year (PPPY) vs US $\$ 44934$ PPPY, respectively). ${ }^{35}$ Furthermore, recent studies have posited that anti-inflammatory therapies approved for $\mathrm{CD}$ are not effective in reducing the morbidity associated with intestinal fibrosis and stricture formation, as evidenced by increasing or plateaued rates of intestinal surgery in CD in recent decades. ${ }^{3812-15}$

Strengths of this study are that it represents the largest real-world analysis in FCD to date. Additionally, we used propensity score matching to control for observable differences in the population. Using this approach, we detected a significant difference between FCD and nonFCD groups in the use of acute care services, especially hospitalisation. Limitations include capture of diagnosis through medical coding, which is subject to errors or missing data. Potential confounders, such as smoking status, and validation of diagnoses with radiologic studies such as MRI were not available in this dataset. For this analysis, differentiation between types of fibrostenosis (ie, inflammatory-type vs fibrotic-type) was not possible using available claims data. In addition, outcomes within claims databases may not be generalisable to the overall population, and certain data elements, such as clinical variables (eg, Montreal classification), may not be captured and controlled for. It is also likely that focusing on obstruction underestimated the impact and prevalence of FCD.

In conclusion, we found that patients with FCD had worse outcomes and higher costs of care than patients with non-FCD. Costs of care were driven by inpatient costs, supporting the high unmet medical need in this subgroup of CD patients. Future prospective longitudinal cohort studies may supplement findings in this study and may further describe areas of unmet need and treatment gaps in this patient population at high risk.

\section{Acknowledgements Editorial support was provided by ApotheCom of San} Francisco, CA.

Contributors MD, GW, EN, and KTP contributed to study design, conception, data analysis, and manuscript writing; CK and FR contributed to study design and interpretation of results and editing the manuscript; KTP was involved in obtaining funding source and overall study concept. All authors approved the final version of the manuscript. KTP is guarantor of the work.

Funding Funded by F. Hoffmann-La Roche Ltd.

Competing interests MD, GW, EN, and KTP were/are employees of Genentech, Inc, and received salary and stock options. MD and GW were no longer employees of Genentech, Inc at the time of manuscript completion. CK has nothing to disclose. FR is consultant to or on the advisory board of Agomab, Allergan, AbbVie, Boehringer Ingelheim, Celgene/BMS, CDISC, Cowen, Genentech, Gilead, Gossamer, Guidepoint, Helmsley Charitable Trust, Index Pharma, Janssen, Koutif, Mestag, Metacrine, Morphic, Origo, Pfizer, Pliant, Prometheus Biosciences, Receptos, RedX, Roche, Samsung, Surrozen, Takeda, TechLab, Theravance, Thetis, and UCB and is funded by NIH, Helmsley Charitable Trust, Crohn's and Colitis Foundation, UCB, Pliant, BMS, Pfizer, Boehringer Ingelheim, Morphic, and Kenneth Rainin Foundation.
Patient consent for publication Not applicable.

Ethics approval This study does not involve human participants.

Provenance and peer review Not commissioned; externally peer reviewed.

Data availability statement No data are available. Not applicable.

Supplemental material This content has been supplied by the author(s). It has not been vetted by BMJ Publishing Group Limited (BMJ) and may not have been peer-reviewed. Any opinions or recommendations discussed are solely those of the author(s) and are not endorsed by BMJ. BMJ disclaims all liability and responsibility arising from any reliance placed on the content. Where the content includes any translated material, BMJ does not warrant the accuracy and reliability of the translations (including but not limited to local regulations, clinical guidelines, terminology, drug names and drug dosages), and is not responsible for any error and/or omissions arising from translation and adaptation or otherwise.

Open access This is an open access article distributed in accordance with the Creative Commons Attribution Non Commercial (CC BY-NC 4.0) license, which permits others to distribute, remix, adapt, build upon this work non-commercially, and license their derivative works on different terms, provided the original work is properly cited, appropriate credit is given, any changes made indicated, and the use is non-commercial. See: http://creativecommons.org/licenses/by-nc/4.0/.

\section{REFERENCES}

1 Crohns and Colitis Foundation of America. The facts about inflammatory bowel disease. New York, NY: Crohns and colitis Foundation of America, 2014. Available: https://www.crohnscoliti sfoundation.org/sites/default/files/2019-02/Updated\%20IBD\% 20Factbook.pdf [Accessed 9 Mar 2021].

2 Satsangi J, Silverberg MS, Vermeire S, et al. The Montreal classification of inflammatory bowel disease: controversies, consensus, and implications. Gut 2006;55:749-53.

3 Cosnes J, Gower-Rousseau C, Seksik P, et al. Epidemiology and natural history of inflammatory bowel diseases. Gastroenterology 2011;140:1785-94.

4 Gomollón F, Dignass A, Annese V, et al. 3Rd European evidencebased consensus on the diagnosis and management of Crohn's disease 2016: Part 1: diagnosis and medical management. J Crohns Colitis 2017:11:3-25.

5 Rieder F, Latella G, Magro F, et al. European Crohn's and colitis organisation topical review on prediction, diagnosis and management of Fibrostenosing Crohn's disease. J Crohns Colitis 2016;10:873-85.

6 Rieder F, Fiocchi C, Rogler G, Mechanisms RG. Mechanisms, management, and treatment of fibrosis in patients with inflammatory bowel diseases. Gastroenterology 2017;152:340-50.

7 Wynn TA, Ramalingam TR. Mechanisms of fibrosis: therapeutic translation for fibrotic disease. Nat Med 2012;18:1028-40.

8 Latella G, Di Gregorio J, Flati V, et al. Mechanisms of initiation and progression of intestinal fibrosis in IBD. Scand J Gastroenterol 2015;50:53-65.

9 Latella G, Rogler G, Bamias G, et al. Results of the 4th scientific workshop of the ECCO (I): pathophysiology of intestinal fibrosis in IBD. J Crohns Colitis 2014;8:1147-65.

10 Rieder F, Bettenworth D, Ma C, et al. An expert consensus to standardise definitions, diagnosis and treatment targets for antifibrotic stricture therapies in Crohn's disease. Aliment Pharmacol Ther 2018;48:347-57.

11 Van Assche G, Geboes K, Rutgeerts P. Medical therapy for Crohn's disease strictures. Inflamm Bowel Dis 2004;10:55-60.

$12 \mathrm{Ma} \mathrm{C}$, Moran GW, Benchimol El, et al. Surgical rates for Crohn's disease are decreasing: a population-based time trend analysis and validation study. Am J Gastroenterol 2017;112:1840-8.

13 Bessissow T, Reinglas J, Aruljothy A, et al. Endoscopic management of Crohn's strictures. World J Gastroenterol 2018;24:1859-67.

14 Chang C-W, Wong J-M, Tung C-C, et al. Intestinal stricture in Crohn's disease. Intest Res 2015;13:19-26.

15 Cosnes J, Nion-Larmurier I, Beaugerie L, et al. Impact of the increasing use of immunosuppressants in Crohn's disease on the need for intestinal surgery. Gut 2005;54:237-41.

16 Lan N, Stocchi L, Ashburn JH, et al. Outcomes of endoscopic balloon dilation vs surgical resection for primary ileocolic strictures in patients with Crohn's disease. Clin Gastroenterol Hepatol 2018;16:1260-7.

17 Thienpont C, D'Hoore A, Vermeire S, et al. Long-term outcome of endoscopic dilatation in patients with Crohn's disease is not affected by disease activity or medical therapy. Gut 2010;59:320-4. 
18 Di Nardo G, Oliva S, Passariello M, et al. Intralesional steroid injection after endoscopic balloon dilation in pediatric Crohn's disease with stricture: a prospective, randomized, double-blind, controlled trial. Gastrointest Endosc 2010;72:1201-8.

19 Gustavsson A, Magnuson A, Blomberg B, et al. Endoscopic dilation is an efficacious and safe treatment of intestinal strictures in Crohn's disease. Aliment Pharmacol Ther 2012;36:151-8.

20 Bettenworth D, Gustavsson A, Atreja A, et al. A pooled analysis of efficacy, safety, and long-term outcome of endoscopic balloon dilation therapy for patients with Stricturing Crohn's disease. Inflamm Bowel Dis 2017;23:133-42.

21 Bettenworth D, Bokemeyer A, Baker M, et al. Assessment of Crohn's disease-associated small bowel strictures and fibrosis on crosssectional imaging: a systematic review. Gut 2019;68:1115-26.

22 Bharadwaj S, Fleshner P, Shen B. Therapeutic armamentarium for Stricturing Crohn's disease: medical versus endoscopic versus surgical approaches. Inflamm Bowel Dis 2015;21:2194-213.

23 Keyashian K, Dehghan M, Sceats L, et al. Comparative incidence of inflammatory bowel disease in different age groups in the United States. Inflamm Bowel Dis 2019;25:1983-9.

24 Wren AA, Bensen R, Sceats L, et al. Starting young: trends in opioid therapy among US adolescents and young adults with inflammatory bowel disease in the Truven Marketscan database between 2007 and 2015. Inflamm Bowel Dis 2018;24:2093-103.

25 Solberg LI, Engebretson KI, Sperl-Hillen JM, et al. Are claims data accurate enough to identify patients for performance measures or quality improvement? the case of diabetes, heart disease, and depression. Am J Med Qual 2006;21:238-45.

26 Govani SM, Lipson R, Noureldin M, et al. Adalimumab persistence for inflammatory bowel disease in veteran and insured cohorts. Am J Manag Care 2018;24:e374-9.
27 Lichtenstein GR, Loftus EV, Isaacs KL, et al. ACG clinical guideline: management of Crohn's disease in adults. Am J Gastroenterol 2018;113:481-517.

28 Park KT, Sceats L, Dehghan M, et al. Risk of post-operative surgical site infections after vedolizumab vs anti-tumour necrosis factor therapy: a propensity score matching analysis in inflammatory bowel disease. Aliment Pharmacol Ther 2018;48:340-6.

29 Louis E, Boverie J, Dewit O, et al. Treatment of small bowel subocclusive Crohn's disease with infliximab: an open pilot study. Acta Gastroenterol Belg 2007;70:15-19.

30 Zorzi F, Zuzzi S, Onali S, et al. Efficacy and safety of infliximab and adalimumab in Crohn's disease: a single centre study. Aliment Pharmacol Ther 2012;35:1397-407.

31 Vasilopoulos S, Kugathasan S, Saeian K. Intestinal strictures complicating initially successful infliximab treatment for luminal Crohn's disease. Am J Gastroenterol 2000;95:2503.

32 Lichtenstein GR, Feagan BG, Cohen RD, et al. Serious infections and mortality in association with therapies for Crohn's disease: treat registry. Clin Gastroenterol Hepatol 2006;4:621-30.

33 Bouhnik Y, Carbonnel F, Laharie D, et al. Efficacy of adalimumab in patients with Crohn's disease and symptomatic small bowel stricture: a multicentre, prospective, observational cohort (CREOLE) study. Gut 2018;67:53-60.

34 Rao BB, Click BH, Koutroubakis IE, et al. The cost of Crohn's disease: varied health care expenditure patterns across distinct disease trajectories. Inflamm Bowel Dis 2017;23:107-15.

35 Manceur AM, Ding Z, Muser E, et al. Burden of Crohn's disease in the United States: long-term healthcare and work-loss related costs. J Med Econ 2020;23:1092-101. 